\title{
Científicos Periféricos, entre Ariel y Calibán. Saberes Institucionales y Circuitos de Consagración en Argentina: Las Publicaciones de los Investigadores del CONICET*
}

\author{
Fernanda Beigel \\ Universidad Nacional de Cuyo (UNCuyo), Mendoza, Argentina. E-mail: \\ mfbeigel@mendoza-conicet.gob.ar).
}

\begin{abstract}
Nuestro símbolo no es pues Ariel, como pensó Rodó, sino Calibán. Esto es algo que vemos con particular nitidez los mestizos que habitamos estas mismas islas donde vivió Calibán: Próspero invadió las islas, mató a nuestros ancestros, esclavizó a Calibán y le enseñó su idioma para entenderse con él: ¿Qué otra cosa puede hacer Calibán sino utilizar ese mismo idioma para maldecir, para desear que caiga sobre él la "roja plaga"? No conozco otra metáfora más acertada de nuestra situación cultural, de nuestra realidad (Retamar, 1971).
\end{abstract}

\section{INTRODUCCIÓN}

$\mathrm{V}$ arios autores sostienen que las lenguas constituyen un sistema idiomático global, una suerte de dimensión lingüística del sistema mundo, que es el producto de relaciones de poder e intercambio, y se construye a la par de sus dimensiones políticas económicas y cultu-

\footnotetext{
* Esta investigación fue financiada por los proyectos INTERCOSSH GA 319974, PICT 2013-0157 de la Agencia Nacional de Promoción Cienítifica y Tecnológica y el PIP 2014-0157 del CONICET. La autora desea agradecer a Dominique Babini, Denis Baranger, Carolina Mera, Breno Bringel y Enara Echart Muñoz, amigas / os y comentaristas críticos/as de las primeras versiones de este trabajo.
}

DADOS - Revista de Ciências Sociais, Rio de Janeiro, vol. 60, n3, 2017, pp. 825 a 865. 
rales (De Swaan, 2001; Heilbron, 2008). En el caso de América Latina, la imposición de una lengua sobre otra fue una forma de violencia simbólica que nació durante la conquista y la colonización, como resultado de la violencia física sobre las comunidades originarias de nuestro continente. Dos lenguas dominantes, el español y el portugués, se establecieron como lenguas oficiales sobre cientos de lenguas indígenas (nahuátl, quechua, aymara, guaraní, mapuche, entre tantas otras), aunque muchas siguieron desarrollándose como forma de resistencia, junto a una serie de tradiciones y culturas que persisten en la actualidad.

La experiencia de la colonialidad produjo una rica tradición de reflexión, que ya en los albores del proceso independentista cuestionaba los efectos de la dominación política y económica sobre lo que nuestros pensadores llamaban la "dependencia intelectual" (Beigel, 2006, 2016). Esta preocupación continuó durante todo el siglo XIX y XX, en medio de álgidos debates entre el nacionalismo y el cosmopolitismo, mientras el español y el portugués se consolidaban como lenguas legítimas al compás de la construcción de los estados nacionales. A medida que Estados Unidos fortalecía su hegemonía militar, política, económica y cultural, el cuestionamiento de la dominación colonial cedió lugar a la impugnación del imperialismo y estas lenguas fueron el terreno de gestación del latinoamericanismo contemporáneo. Es por ello que, si bien hacia dentro de América Latina el español y el portugués verbalizan la colonialidad, desde una perspectiva global se presentan actualmente como lenguas dominadas.

Los científicos o científicas no son protagonistas principales de esas batallas identitarias de nuestro continente, pero participan de las disputas culturales y políticas de la circulación internacional del conocimiento. Hay académicos con un perfil "Próspero" que escriben en inglés, su lengua materna, habitan en los "centros de excelencia" de los países poderosos, y poco saben (o creen que poco necesitan aprender) otros idiomas. En la periferia, también hay científicos que escriben en inglés, un idioma que aprendieron en la formación escolar y/o en el entrenamiento científico. Viven en países del Sur, pero se despliegan en circuitos internacionalizados, que han sido anexados al reino de los sistemas de indexación, los rankings de revistas y las mediciones bibliométricas. Etéreos, "puros", como Ariel, no encuentran el sentido de escribir en español o en portugués porque para ellos la ciencia es "universal" y se comunica en esta lingua franca. Por otro lado, hay científicos con las características de Calibán que resisten la mundialización 
académica escribiendo en su idioma materno, publicando en revistas no indexadas, o recluyéndose en islas, sostenidas por la endogamia.

Proponemos como disparador analítico de este trabajo una metáfora latinoamericanista por excelencia, que se remite a los múltiples ensayos que se han escrito en la región sobre la obra de Shakespeare, La Tempestad, y sus tres personajes principales: Próspero, el conquistador de una isla que se convertiría en su reino durante el exilio; Ariel, su espíritu consejero; y Calibán el nativo esclavizado. El uruguayo José Enrique Rodó argumentó, en 1900, que América Latina estaba representada por "Ariel", pura espiritualidad y belleza, frente al materialismo y al expansionismo norteamericano. Más tarde, el cubano Roberto Fernández Retamar (1971) sostuvo que éramos "Calibanes", nativos colonizados, que aprendimos el idioma de Próspero para maldecirlo, para producir una insurrección que hiciera caer sobre el conquistador "la roja plaga".

Pareciera que hoy los científicos arielescos encarnan fielmente el papel de espíritus al servicio de Próspero. Los académicos "nativos", por su parte, están bastante alejados de la insurrección: resisten a Próspero, pero construyen espacios de poder que someten a otros Calibanes. La masculinidad atraviesa la metáfora y nuestro campo de observación, efectivamente, desde que se disputan formas de construcción del prestigio y autopercepciones de superioridad entre unos y otros. La singularidad de estos personajes y su fuerza simbólica nos permitirán presentar dos perfiles opuestos que construiremos con fines analíticos para analizar los circuitos de consagración en la periferia. Con ello no queremos afirmar que existan sólo dos estilos de producción y publicación, sino que es posible tipificar dos polos con direccionalidades distintas, entre los cuales hay diversas prácticas académicas que conviven conflictivamente.

En trabajos recientes (Beigel, 2013, 2014a) hemos analizado cómo se construyó históricamente el sistema académico mundial y en qué medida modificó la geografía científica a través de un sistema de publicaciones que fue "universalizando" una lengua y un estilo de escritura. Describimos cómo se jerarquizó un circuito llamado de "corriente principal" (mainstream) que fue muy eficaz, durante cuatro décadas, para dotar de prestigio internacional a algunos centros de excelencia y ciertas disciplinas, mientras volvía periféricas a comunidades científicas enteras que no publicaban en las revistas aceptadas por el Institute for Scientific Information - ISI (ex Thomson Reuters/Web of Science, 
hoy Clarivate). También investigamos el avance del movimiento de acceso abierto, especialmente el circuito latinoamericano de publicaciones científicas y los procesos de "regionalización" del prestigio académico que estos circuitos favorecen, particularmente en las ciencias sociales y en las humanidades (Beigel, 2014b). Fuera de esos circuitos internacionales también pudimos observar empíricamente la existencia de circuitos locales, nutridos de numerosas revistas sin indexación, publicadas mayormente en papel, que tienen una circulación restringida, pero verifican la productividad de los espacios académicos no internacionalizados (Beigel y Salatino, 2015). Esto ocurre porque la dependencia académica altera las culturas evaluativas nacionales y profundiza la heterogeneidad estructural. Pero no "coloniza" el campo, sino que segmenta los circuitos de consagración.

En el presente artículo emprendemos una indagación que apunta a conocer la dinámica endógena de los campos periféricos para comprender mejor las orientaciones contrapuestas que se desarrollan en el proceso de construcción de una elite académica "bifronte". Argentina es un caso interesante para analizar estilos de producción y circulación porque ha vivido recientemente una expansión de sus capacidades de investigación sin precedentes, basada en una inyección fuerte de recursos, con una orientación de tipo "nacionalista" visible en el sistema de becas, la política de incorporación de investigadores y el fortalecimiento de las carreras de doctorado. Se trata de un campo científico dinámico, predominantemente público, que triplicó la cantidad de investigadores full-time en la última década (de 3.694 en 2003 a 9.236 en 2015), repatrió más de mil investigadores argentinos que habían emigrado en épocas de crisis y capitalizó las redes que éstos construyeron durante sus experiencias en el exterior. Entre 2004 y 2015 se produjo un aumento de la cantidad de carreras de doctorado y doctores formados en todas las áreas, fruto de una política de becas para realizar el doctorado exclusivamente en el país ${ }^{1}$, dirigidas no sólo a ciudadanos argentinos sino también extranjeros. Se convirtió, así, en un polo de atracción para estudiantes latinoamericanos, porque las universidades públicas ofrecen programas de calidad a costos mucho más bajos que otros países de la región, revitalizando su antiguo rol como centro periférico (Beigel, 2010).

Paralelamente, sin embargo, se profundizó la polarización entre los científicos integrados a los estilos de producción dominantes en el sistema académico mundial y los que tienen una agenda más endógena. 
Aunque conviven tendencias autónomas y heterónomas tanto en el espacio internacionalizado como en el espacio más orientado a lo local. En este artículo intentaremos mostrar que la dinámica de esos espacios está ligada a los capitales en juego en el campo, las asimetrías institucionales, la incidencia de culturas evaluativas "alteradas" y a la existencia de circuitos segmentados de consagración. Buscaremos, así, explorar las formas de construcción social del prestigio de unas elites académicas para las que tiene poca importancia la "cuna" y la fortuna, pero que se juega en la disputa entre dos tipos de prestigio, uno internacional versus otro local/nacional.

La primera inquietud que movilizó este trabajo fue la constatación de que los y las investigadores del Consejo Nacional de Investigaciones Científicas y Técnicas (CONICET) escriben básicamente papers en inglés y publican en circuitos de corriente principal, pero esas capacidades lingüísticas no surgen de una formación académica en el exterior. Prácticamente la totalidad se graduó en universidades públicas argentinas y más del $90 \%$ se doctoró en el país. Tampoco puede ser atribuible a una diferencia de clase, como veremos enseguida, puesto que Arieles y Calibanes son igualmente "herederos". Por otra parte, existen estudios disponibles (Lillis y Curry, 2010; Gerhards, 2014) que muestran que las capacidades lingüísticas adquiridas en la socialización no garantizan la publicación científica en las revistas con alto factor de impacto. Para explicar esta aparente paradoja ponemos en relación la historia del campo y los saberes institucionales que se reproducen en el proceso de formación académica, diferenciando estilos de publicación y circuitos de consagración.

Finalmente, nos concentramos en el perfil internacionalizado, a través de un estudio empírico de las publicaciones de los y las investigadores del CONICET. Para ello trabajamos con una base de datos que incluye la trayectoria curricular de todos los investigadores del organismo. Dentro de ella, construimos una subpoblación compuesta por quienes se presentaron a promoción en los últimos años y seleccionaron lo que consideraron como las " 5 producciones científicas más relevantes de su carrera". Se trata de un total de 23.852 publicaciones. Examinamos este corpus de publicaciones por disciplina, edad, tipo de publicación e idioma. Luego, nos concentramos en una muestra con el objetivo de analizar las publicaciones por país y circuito. La base de datos del universo de investigadores que utilizo en este trabajo fue construida en nuestro Programa de Investigaciones sobre Dependencia Académica 
en América Latina (PIDAAL, CONICET-UNCuyo, Mendoza, Argentina) a partir de una solicitud formal que hicimos al organismo para acceder a la información contenida en el Sistema Integral de Gestión y Evaluación (SIGEVA) ${ }^{2}$. La base de datos del universo se construyó con información existente a diciembre de 2014, y la subpoblación de quienes se presentaron a promoción, así como la muestra para el análisis de los circuitos con información actualizada a junio de 2015. En lo que sigue, mediante un diálogo entre la observación cualitativa y cuantitativa, esperamos ofrecer una radiografía del estilo de publicación de una parte de las elites académicas argentinas afines al perfil de Ariel. Para próximos trabajos dejamos el análisis empírico de las publicaciones de estilo Calibán.

\section{LA CONSTRUCCIÓN DEL PRESTIGIO DE LAS ELITES ACADÉMICAS EN ARGENTINA: HABITUS LOCAL Y HABITUS INTERNACIONAL}

Despojado del racismo biológico o mental que inspiró los postulados sobre la "naturalidad" de la superioridad de las minorías, el concepto de elite permite observar formas de consagración por la que ciertos grupos dominantes se reconocen y buscan ser reconocidos como sector distintivo de la sociedad (Gérard y Wagner, 2015). Los estudios sobre las elites realizados en y sobre Francia sugieren que la base social de las elites se expande cuando se pasa del polo económico al intelectual. Por eso es una constante estructural de larga duración el hecho de que los universitarios son la fracción dominada de la burguesía (Charle, 2009). Pero la homogeneidad de esas clases dirigentes, y el consenso sobre su discurso republicano y meritocrático está muy lejos del panorama que se presenta en las elites de países dependientes como la Argentina. Si alguna vez existió, la "burguesía nacional" nunca se constituyó como clase hegemónica con un discurso coherente y legítimo. Y la última dictadura se encargó de minar lo que quedaba de ella en su actividad central que era la producción industrial (Basualdo, 2003:7). Aún con la reciente revitalización/ extranjerización de este sector, hoy los contornos de las elites económicas se identifican más bien con los grupos profesionales de altos ingresos, a los que Luci (2012) define como "manageriales". Así, vincular sociológicamente las elites intelectuales en Argentina con la trayectoria de una clase sería tan superfluo como inviable, pero es importante comprender cómo se construye su discurso meritocrático. Exógenamente, en oposición a esas elites económicas, y endógenamente, a partir de la disputa entre los científicos "internacionalizados" y los que tienen un anclaje más bien local. 
Genéricamente, los/las "universitarios" y "científicos" argentinos se perciben a sí mismos como heterogéneos, por su origen social, e igualitarios, por su valoración del esfuerzo. Comparado con otros países latinoamericanos, el carácter predominantemente público del campo científico y de la educación superior en Argentina conduce a suponer que existe igualdad de condiciones para que todos aquellos que tienen vocación intelectual puedan ingresar al mundo académico. Las universidades públicas ofrecen estudios de grado gratuitos, así como programas de posgrado prestigiosos y poco onerosos. A diferencia de la Prueba de Aptitud Académica en Chile, en Argentina no hay una competencia nacional que ordene una jerarquía de candidatos a la universidad según el desempeño en esas pruebas de ingreso. La matrícula de estudiantes de pregrado/grado en universidades públicas es bastante más alta que en el ámbito privado: para 2012 era del 79\% (SPU, 2012:38). Para 2013, en el quintil más pobre de ingresos el porcentaje de estudiantes terciarios en instituciones públicas era del $80,9 \%$ y en el quintil más rico alcanzaba un $69,7 \%$, una proporción que supera con creces la participación del quintil más rico en la educación pública de otros países que eligen preferentemente la educación privada. Históricamente, Argentina ha tenido una de las tasas netas de escolarización universitaria más elevada de América Latina: en 2013, ascendía a $29,8 \%$. Ahora bien, analizada por quintiles de ingreso, para el quintil más pobre esta tasa baja a 19,1\% y para el quintil más rico asciende a 54,1\% (SEDLAC, 2015).

Como sostienen Tiramonti y Ziegler (2008), la tradición universitaria argentina, laica, pública y gratuita, forma parte de un imaginario igualitarista, de una sociedad reacia a reconocer las jerarquías sociales, y mucho menos a asociarlas a los privilegios en el trato social. Acorde a un modelo de integración basado en la capacidad del Estado para cohesionar e incorporar una parte importante de la clase trabajadora y en la expansión de las clases medias asalariadas, la educación pública brindó efectivamente canales de movilidad social ascendente. Sin embargo, las bases que sustentaban ese imaginario perduraron hasta la última dictadura militar. Con la crisis de 1989 y el ajuste neoliberal se extendió una pauperización y una sensación de fin de ciclo que auguraba que ese modelo de integración se había modificado. El Estado delegó a la "libre competencia" la formación de elites y los sectores más privilegiados fueron colonizando ciertas instituciones, proceso que derivó en el éxodo de educación pública por parte de los sectores medios y una "democratización segregada" (ibidem:15). Esto modificó la 
composición de la matrícula educativa: mientras en el nivel universitario se mantiene el predominio de las instituciones públicas, al analizar las trayectorias educativas la situación se invierte en favor de las escuelas primarias y secundarias privadas ${ }^{3}$.

En coincidencia con el resto de la literatura disponible, Ezcurra (2011) comprueba que la permanencia y el egreso de la universidad pública argentina está fuertemente marcada por el origen social, porque se facilita con el paso por instituciones privadas de educación media. Como ha sostenido Chiroleu (2012) la universidad pública es una institución escogida preferentemente por los estratos medios y medio altos, más allá de la "visita" temporaria de otros grupos de reducido volumen provenientes de estratos más bajos en algunas universidades y especialmente en algunas carreras. Las desigualdades no sólo son atribuibles a las trayectorias educativas previas, sino también a la creciente heterogeneidad del sistema universitario argentino que verifica un proceso de diferenciación y segmentación creciente (ibidem:96-98).

Esta selectividad tendría que tener una incidencia "positiva" en las capacidades en lenguas extranjeras de los estudiantes universitarios, puesto que existe una apuesta fuerte en la enseñanza del inglés en las escuelas de gestión privada y, por el contrario, una muy baja en la educación primaria y media pública. Pero, como señala Bein (2010), en Argentina no existe una política lingüística de Estado, lo cual es evidente en las leyes federales de educación que estipulan la enseñanza de una sola lengua extranjera, pero sin determinar cuál. Finalmente, la creciente heterogeneidad del sistema universitario argentino explica que en algunas universidades nacionales, y sobre todo en algunas carreras (ciencias sociales y humanidades típicamente), tengan mayor presencia estudiantes provenientes de grupos sociales con menor capital cultural y lingüístico.

En la construcción de una trayectoria científica operan factores anclados en la socialización, como el capital cultural, y lo que Bourdieu y Passeron llaman el savoir-vivre construido desde el nacimiento en las familias. "Toda enseñanza, y más particularmente la enseñanza de la cultura (incluso la científica), presupone implícitamente un cuerpo de saberes, de saber-hacer y sobre todo de saber-decir que constituye el patrimonio de las clases cultivadas" (2003 [1964]:38). Así, no cabe duda que nuestras elites se componen mayoritariamente de "herederos" en el sentido atribuido por Bourdieu, pero lo que interesa aquí es 
comprender por qué un itinerario de heredero da lugar a un académico/a que, en términos de Xavier De Brito (2004) desarrolla un habitus local y otras/os que devienen en un habitus internacional. En la construcción del prestigio académico intervienen muchos elementos relacionados con la estructura del campo, así como factores exógenos (circuitos de publicación, flujos de movilidad académica, financiamiento, redes transnacionales de investigación colaborativa, entre otros).

Para comprender de qué manera se articulan todos estos factores en el caso argentino, es necesario poner en juego la historia del campo científico-universitario, calibrando el peso de la internacionalización en las formas de construcción local del prestigio. En otros trabajos hemos analizado históricamente cómo se edificaron - por caminos relativamente paralelos, asentándose con más fuerza en determinadas disciplinas científicas y en ciertas instituciones - dos principios de legitimación diferentes que marcaron a fuego la illusio de las elites académicas en Argentina. Por una parte, el prestigio institucionalmente reconocido, vinculado con el poder universitario y el capital militante, sobre todo dominante en las universidades del interior, y especialmente en las ciencias sociales y humanas. Por otra, un prestigio internacionalmente reconocido, resultante del capital científico "puro", una illusio fuertemente valorizada en un organismo autónomo como el CONICET, en el que siempre han dominado las ciencias exactas y naturales (Beigel, 2010; 2013), algo también habitual en órganos homólogos en otros países de América Latina.

Esta doble vía para la construcción del prestigio académico se explica en buena medida por la tensión entre el CONICET y las universidades nacionales, dos espacios que vivieron un profundo divorcio durante la última dictadura (1976-1983), cuando se crearon más de cien institutos de investigación en el CONICET, desvinculados de las universidades (Bekerman, 2013). Además de cumplir con el objetivo inmediato de despolitizar el campo, una de las principales consecuencias de esta intervención militar fue la escisión entre el ambiente de la investigación y la actividad docente, que se promovió con el aislamiento de aquellos institutos respecto de la vida universitaria. Durante este período se encumbraron grupos de las ciencias exactas y naturales, que concentraron la mayor cantidad de cargos jerárquicos en el CONICET y moldearon criterios de evaluación de la ciencia atados al "reconocimiento internacional". Resultaba mucho más fácil implantar exigencias de internacionalización y publicación estilo ISI en un organismo descentra- 
lizado. Mientras tanto, las universidades nacionales, con su autonomía institucional y la tradicional politización de sus claustros, fueron siempre más refractarias a la imposición de normas exógenas de producción y evaluación.

Con el retorno de la democracia en 1983, se hicieron esfuerzos para reconectar al CONICET con las universidades nacionales. Sin embargo, en 1990 sobrevino el ajuste neoliberal y el gasto público en ciencia y técnica disminuyó (con excepcionales repuntes) desde 1988 hasta 2002. En estos años, las universidades públicas y el CONICET sufrieron duros embates que parecían indicar que la ciencia argentina estaba en decadencia y que la valorización social de la educación pública declinaría sin retorno. Fue allí cuando se produjo la emigración de científicos, el cierre del ingreso en la carrera del CONICET, la reducción de becas, el ahogo financiero de las universidades públicas y la explosión del crecimiento de las universidades privadas. La crisis de 2001 encontró al sistema científico en franco ahogo financiero y en 2002 el crecimiento de investigadores del alcanzó el signo negativo. La pirámide poblacional del CONICET estaba envejecida, con la mayor parte de sus investigadores en las jerarquías de independiente a principal (en aquel entonces, mayores de 45 años) y, sostenida por una base pequeña y desproporcionada de investigadores de las categorías inferiores, adjuntos y asistentes. Los/as científicos y universitarios que sobrevivieron a la crisis de 2001-2002 parecían una elite en extinción. En ese tiempo, la publicación en inglés, en revistas con alto factor de impacto se convirtió en la principal meta de los investigadores que observaban el desdén con el que los funcionarios se referían a la ciencia en el país ${ }^{4}$. Se fue profundizando, así, la identificación de los investigadores de CONICET con la consagración "internacional" contra un ambiente nacional de restricciones financieras y falta de perspectivas.

Nuestros "Arieles" sentían que su superioridad residía en el capital científico "puro" que desplegaban cuando dictaban conferencias en el exterior o publicaban en inglés, mientras que "otros" quedaban reducidos a publicar en español, y en el país, porque no lograban resultados de investigación valiosos para la comunidad científica global. Sin embargo, no fueron simplemente científicos que tuvieron éxito porque supieron desarrollar estrategias adecuadas de inserción en el circuito de corriente principal, o porque su origen social les permitió aprender inglés. La viabilidad de esas estrategias dependió de la articulación de capitales heredados y adquiridos, es decir, del uso social de lo que 
Wagner (2007) ha llamado el capital cosmopolita, pero también de un conjunto de competencias obtenidas durante la formación académica. Veamos ahora el papel que juegan los saberes institucionales en la diferenciación de estos perfiles.

\section{UNA ELITE BIFRONTE: CAPITAL INSTITUCIONAL, ESTILOS DE PRODUCCIÓN Y CIRCUITOS DE CIRCULACIÓN}

Si bien existen muchas tensiones en el campo científico-universitario argentino, en este artículo nos interesa especialmente analizar aquellas que permitan comprender el funcionamiento de principios de consagración diferenciados. Una de las tensiones más persistentes hasta la actualidad es la disputa entre los académicos con arraigo exclusivo en las universidades y los investigadores e investigadoras del CONICET que tienen dedicación de tiempo completo a la investigación, pero tienen también (o pretenden tener) un cargo docente. A la disputa histórica generada entre las universidades y el CONICET durante la última dictadura, se había sumado el conflicto entre los exiliados que se formaron en el exterior y los expulsados que se quedaron en el país con restringidas posibilidades de formación y publicación. Esta confrontación se resignificó en las nuevas generaciones a través de la oposición entre los profesores con trayectoria básicamente docente frente a los investigadores del CONICET, con antecedentes principalmente de investigación. Estos últimos eran vistos por los primeros como candidatos "externos" que aparecían en los concursos regulares-efectivos, mientras los "internos" llevaban muchos años dictando esa materia, designados a través de contratos.

El enfrentamiento no atraviesa actualmente por igual a todas las instituciones y áreas científicas sino especialmente aquellas con menor desarrollo de la investigación. En algunas universidades no-metropolitanas se han generado, entre otras modalidades de defensa, modificaciones en los reglamentos de los concursos con el objetivo de poner en valor la docencia frente a la investigación y la "trayectoria docente" en la propia institución ${ }^{5}$. Por parte del CONICET, la disputa se manifiesta en el orden de los datos de filiación de las publicaciones de sus investigadores (véase la reciente Resolución del Directorio del CONICET no 515/2016).

La autopercepción de "superioridad" de los profesores universitarios frente a los contendientes "externos" se basa en el conocimiento de la 
agenda local de discusión, la participación en la construcción de las instituciones, el dominio pedagógico y la experiencia docente, que es considerada el basamento del funcionamiento de la universidad. Parte de esa autopercepción fue alimentada durante la década de 1990, una etapa de ajustes financieros en todo el campo científico-universitario en la que la mayoría de los cargos fueron interinos y los investigadores que lograban ingresar al CONICET lo hacían en institutos que estaban fuera de la universidad. Los profesores que desarrollaron una trayectoria docente y no pudieron (hay también quienes no quisieron) entrar al CONICET, vivieron un ambiente de restricción que motorizó su compromiso personal para asegurar el funcionamiento de las carreras de grado. Se produjo, así, en estos perfiles, una conjunción entre el prestigio docente, un saber-hacer construido en una experiencia institucional refractaria a la influencia externa y una especie de capital social que se adquiere en la dinámica política de las facultades.

A diferencia de los investigadores del CONICET, acostumbrados a ser examinados por comisiones con criterios de evaluación cada vez más internacionalizados, los profesores universitarios se desenvuelven en instituciones con autonomía y autarquía, muchas de las cuales resistieron la implementación de la evaluación externa y acreditación que se impuso durante los años de 1990. Esto favoreció la extensión de un discurso horizontalista que cuajó en la idea de un profesorado "popular" frente a un investigador que habitaba en su torre de marfil. Sin embargo, la dinámica universitaria también engendró sus propios aristócratas y un discurso academicista para sostener las decisiones de los consejos y los decanos. Los concursos docentes dependen de regulaciones propias y en general, los jurados se conforman en una dinámica endógena, condicionada por los grupos de poder en los consejos directivos de las facultades. Una endogamia enquistada en la propia práctica institucional, de la que poco se habla "puertas afuera". Follari (2008) argumenta que desplegando una ideología que se ufana de la "pureza" y la transparencia académica, se desarrolla un comportamiento corporativo en función de intereses individuales o de grupos. Detrás de la "autonomía académica" se justifica la energía puesta en rencillas internas, relegando a los profesores al silencio frente a los problemas sociales relevantes.

Esta mirada descarnada de la práctica académica en las universidades señala comportamientos institucionales reales y comunes al sistema universitario argentino en su conjunto. Sin embargo, pasa por alto la 
especificidad de la illusio que se juega en su interior: el prestigio docente, como forma de capital académico institucionalmente reconocido. $Y$ se obturan formas relativamente autónomas de politización que vienen desarrollándose en la universidad durante todo el siglo XX y que no pueden ser reducidas a un mero velo que recubre la ideología de intereses particulares. Se trata de saberes específicos que se juegan en esas relaciones de poder y que son requeridos para acceder a posiciones dominantes en el mundo universitario.

Como argumentan Gérard y Wagner (2015), los saberes que fabrican las elites no son nunca exclusivamente de orden académico, conocimientos teóricos o aplicados, sino también un saber-hacer y un saber-ser. La seguridad de tener el buen derecho a ocupar una posición de privilegio, la capacidad de reconocer y apreciar a los miembros de su grupo forma parte de las cualidades que define una elite. Esos saberes se cultivan en las instituciones que los forman y para ser eficaces, siempre deben estar asociados a ciertos tipos de recursos sociales y políticos. Los saberes institucionales son, así, competencias de interacción que aseguran el reconocimiento de los pares y que son distintas de las competencias de los no-elegidos. La elite se construye a la vez en la búsqueda de una consagración por arriba y por abajo porque el principio de su superioridad debe ser aceptado por aquellos que ésta pretende dominar (ibidem:5).

Entre las propiedades estructurales de los campos científicos y las propiedades hechas cuerpo en los agentes existe, precisamente, un conjunto de capitales simbólicos que ejercen esa "magia", ese poder de hacer creer y hacer valer, reconociendo y distinguiendo. Para comprender el funcionamiento y reproducción de los saberes de institución, es útil recordar la distinción bourdiana entre los "tres estados" del capital cultural: incorporado, objetivado e institucionalizado. Mientras el primero está anclado en un individuo a través de su socialización familiar y educativa, el segundo se materializaría en este caso en productos o teorías académicas. El capital cultural institucionalizado en un título tiene una autonomía relativa respecto del portador y su valor simbólico excede las capacidades y disposiciones adquiridas por el individuo en las instituciones de formación (Bourdieu, 1979).

Ahora bien, en un campo científico periférico, estructuralmente heterogéneo y con universidades públicas fuertemente autónomas como es Argentina, el pase mágico para vivir en el reino de Arieles o Calibanes no lo aporta sólo el título o el prestigio de la institución de formación. 
Aunque existe una fuerte endogamia que muestra que el título es valioso en el reclutamiento, esa no es condición suficiente ni tampoco garantiza igualdad de condiciones a contendientes graduados en la misma institución. El diferencial está en una serie de saberes institucionales que se adquieren con el ingreso a la experiencia docente o de investigación. Un saber-hacer y un saber-ser que se aprende con la participación en las cátedras, con la batalla por los cargos, en el aprendizaje cotidiano en las salas con otros becarios, del oficio transmitido por investigadores exitosos, el conocimiento del estilo de publicación acumulado en el instituto en el que se desarrollan sus actividades o las redes del equipo de trabajo. Este "capital institucional" no se reduce al título, sino que se objetiva en saberes en estado "incorporado" que pesan al momento de ingresar en la carrera de investigación o en la docencia, en la construcción de un oficio y un saber-decir que es palpable en la redacción de una postulación a un concurso docente, en el ingreso a carrera del CONICET, o un proyecto para competir en las agencias que otorgan subsidios. En otras palabras, un postulante proveniente de una universidad prestigiosa no tiene mejores posibilidades de ingresar al CONICET porque su título es, por ejemplo, de la Universidad de Buenos Aires (UBA), sino porque su paso por esa institución le dio un conjunto de saberes, una serie de redes y una particular habilidad para construir una carrera académica con un estilo de producción y un perfil internacionalizado, acorde a las expectativas reinantes en ese organismo. Puede decirse, entonces, que este "capital institucional" y los saberes que entraña constituyen un tipo particular de capital social.

Con el recurso al personaje de Ariel hemos dibujado el perfil de los científicos de una institución como el CONICET, cuyo ingreso y promoción surge de una competencia nacional que está ligada a los criterios "prósperos" del sistema académico mundial: las publicaciones en revistas indexadas, preferentemente en inglés y en circuitos de corriente principal, medidas según su factor de impacto y los rankings. Con la metáfora de Calibán, tratamos de tipificar a los profesores que concursan bajo reglas de cada universidad, con una orientación más bien local, cuya carrera depende de la trayectoria docente, la participación en la gestión institucional y, en menor medida, de los antecedentes de investigación o las publicaciones que pueden ser en español y en revistas no indexadas.

Ambos perfiles concentran poder de instituir y consagrar, pero detentan capitales que se valorizan de manera distinta según la institución donde se ponen en juego un profesor o profesora titular de una univer- 
sidad de provincia con antecedentes de gestión y de docencia perdería seguramente un concurso para ingresar al CONICET, mientras que un investigador o una investigadora del CONICET con muchas publicaciones internacionales (pero pocos antecedentes docentes) probablemente no tendría un buen resultado en un concurso en una universidad de provincia. Se diferencia, así, un candidato o una candidata que dispone de un prestigio académico (local) institucionalmente reconocido, saberes propios de la cultura universitaria en la que se inserta y cierta dosis de capital social (relaciones con el poder universitario, participación en comités y redes universitarias) frente a un candidato o candidata que dispone de prestigio científico ("internacional") nacionalmente reconocido, saberes propios del oficio del investigador/becario de una institución como el CONICET y otro tipo de capital social (relaciones con equipos de investigación reconocidos, participación en comisiones asesoras, asociaciones académicas, revistas científicas, etc.).

A estas alturas, se podría pensar que nuestro argumento conduce a afirmar que los investigadores e investigadoras del CONICET son todos de estilo Ariel, mientras las personas que se desempeñan como docentes-investigadores de las universidades nacionales son, en su totalidad, Calibanes. Pero las cosas no son tan simples. Y la metáfora de Ariel y Calibán es sólo eso, una metáfora que guarda una relación interpretativa con dos orientaciones marcadamente opuestas en el campo científico-universitario argentino, en medio de las cuales hay un continuum de grises y mestizajes. Al poner en juego no sólo la pertenencia institucional, sino también la disciplina, encontramos diversos perfiles intermedios. ¿Pero quiénes, son empíricamente, estos profesores e investigadores de elite en Argentina?

En Beigel, Bekerman y Gallardo (2016) analizamos exhaustivamente la composición de la población de académicos argentinos y las asimetrías geográficas e institucionales dentro de dos grandes conglomerados: las universidades y el CONICET. Los docentes de universidades nacionales (públicas) suman 166.810 en todas las categorías, pero constituyen un mundo muy heterogéneo en el que sólo un 15\% registra actividades de investigación acreditadas y el 10\% del total tiene título de doctorado (SPU, 2013:236, 316). Es un universo complejo en el que puede disecarse una sub-población de docentes-investigadores que están categorizados en el Programa de Incentivo a los Docentes Investigadores (PIDI), y que participan activamente de las culturas evaluativas en pugna. Se trata de un universo que incluía en 2012, la última información oficial disponible, 24.014 profesores. El 64\% de estos docentes- 
investigadores reviste dedicación exclusiva y el $77 \%$ pertenece a las categorías inferiores (III, IV y V). Entre estos agentes, muchos de ellos "nuevos jugadores", pesa la cultura evaluativa de estilo Calibán que define las condiciones para ascender de categoría PIDI o aumentar la dedicación docente.

Cinco universidades (Universidad de Buenos Aires - UBA; Universidad Nacional de La Plata - UNLP; Universidad de Córdoba - UNC; Universidad de Rosario - UNR y Universidad Nacional de Tucumán UNT) concentran el 58\% del total de la categoría más alta (I) del sistema de incentivos $(1,298 / 2,235)$. Especialmente la UBA, tiene el 24,5\% de los docentes categoría I de todo el país, buena parte de los cuales son también investigadores e investigadoras del CONICET con categorías superiores. La participación de la UBA disminuye a medida que descienden jerárquicamente las categorías, llegando al $10-12 \%$ en las categorías IV y V (SPU, 2013), con lo cual su alta participación en las categorías superiores no se explica sencillamente porque es una universidad masiva que ocupa gran parte de todas las categorías.

El papel dominante que tiene la UBA en el universo de categorías docentes superiores se manifiesta también en la morfología del CONICET. Del total de los investigadores (7.905), un 21,3\% tienen lugar de trabajo en la UBA, y en las ciencias sociales ese porcentaje sube al 29\% (494/1713). Este lugar de trabajo crece a medida que aumenta la categoría: un tercio del total de los investigadores superiores tienen lugar de trabajo en esa universidad. $73 \%$ de los investigadores tienen un cargo docente en una universidad nacional (5.816) y el 25,7\% (1.498) de estos pertenece a la $\mathrm{UBA}^{6}$.

Ahora bien, la concentración de la formación de grado y posgrado de los investigadores del CONICET en la UBA es aún más fuerte que su peso como lugar de trabajo de los investigadores y dice mucho acerca de la segmentación de las elites académicas en Argentina. El 32,5\% del total de investigadores del CONICET se graduó en la UBA y el 30,3\% del total se doctoró en esa universidad. Muy lejos siguen los que se doctoraron en la UNLP ( $5 \%$ ) y en la UNC $(2,8 \%)$. Como vemos en la Tabla 1, el predominio del título de doctor en UBA varía según el área científica.

Aunque resulta lógico que un título obtenido en la universidad más prestigiosa del país incida en una carrera académica exitosa, sería una simplificación atribuir un papel determinante en la selección del ingreso al CONICET a la "tiranía del título inicial". El peso del título depen- 
Científicos Periféricos, entre Ariel y Calibán. Saberes Institucionales y Circuitos...

Tabla 1

Investigadores del CONICET con Título Doctoral de la Universidad de Buenos Aires, por Área Científica, n=2.398/7.905 (2014)

\begin{tabular}{l|c|c|c}
\hline Área & $\begin{array}{c}\text { Título Dr. } \\
\text { UBA }\end{array}$ & $\begin{array}{c}\text { Total de } \\
\text { Investigadores }\end{array}$ & $\%$ \\
\hline Ciencias sociales y humanidades & 608 & 1.710 & 35,5 \\
Ciencias exactas y naturales & 486 & 2.012 & 24,1 \\
Ciencias agrarias, ingenierías y materiales & 295 & 1.749 & 16,8 \\
Ciencias biológicas y de la salud & 1.009 & 2.434 & 41,5 \\
\hline Total & $\mathbf{2 . 3 9 8}$ & $\mathbf{7 . 9 0 5}$ & $\mathbf{1 0 0 , 0}$ \\
\hline
\end{tabular}

Fuente: Elaboración propia a partir de la Base de Datos PIDAAL-Investigadores CONICET (diciembre, 2014).

de del valor socialmente atribuido en cada comunidad científica y la observación que hemos hecho de procesos de evaluación de ingreso al CONICET no muestra una particular valoración de la universidad que otorgó el título de doctor/a. Esto es también claro en relación con el prestigio de los títulos extranjeros que no parecen tener grandes recompensas, puesto que la titulación doctoral en el país, para todas las disciplinas, promedia el $91 \%$ del total de investigadores.

De hecho, la relación misma entre internacionalización y titulación en el exterior se pone en tela de juicio al observar el universo actual de investigadores del CONICET. Las disciplinas que mayor titulación en el exterior presentan son las ciencias sociales y humanas (34\%), mientras sus publicaciones internacionales son francamente menores que en el resto de las áreas científicas. Las otras tres áreas científicas presentan formaciones doctorales predominantemente en Argentina, con un $92 \%$ en las ciencias exactas y naturales, un $88 \%$ en las ciencias agrarias e ingenierías y un $95 \%$ en las ciencias biológicas y de la salud. Y, como veremos más abajo, prácticamente publican sólo en inglés y en el circuito mainstream.

Tabla 2

Investigadores del CONICET según el País del Título Doctoral, por Área Científica $n=7.343^{7}$

\begin{tabular}{l|c|c|c}
\hline Área & Argentina & Exterior & Total \\
\hline Ciencias sociales y humanidades & 1.233 & 427 & 1.660 \\
Ciencias exactas y naturales & 1.712 & 148 & 1.860 \\
Ciencias agrarias, ingenierías y materiales & 1.390 & 175 & 1.565 \\
Ciencias biológicas y de la salud & 2.135 & 123 & 2.258 \\
\hline Total & $\mathbf{6 . 4 7 0}$ & $\mathbf{8 7 3}$ & $\mathbf{7 . 3 4 3}$ \\
\hline
\end{tabular}

Fuente: Elaboración propia a partir de la Base de Datos PIDAAL-Investigadores CONICET (diciembre 2014). 
Más que el peso del título, nuestro estudio sugiere que para explicar el ingreso en el CONICET y su estilo de producción, las relaciones causales deben buscarse en las competencias y los saberes institucionales que ciertos espacios académicos prestigiosos ofrecen. Durante la formación de grado y posgrado se adquieren conocimientos y habilidades que son valiosos para favorecer el desempeño de sus portadores en una cultura evaluativa internacionalizada y un savoir-vivre indispensable para ascender exitosamente en ella. Estos saberes no siempre garantizan carreras docentes en aquella institución, pero son eficaces para ingresar al CONICET porque estructuran los criterios de evaluación del propio organismo, dada la presencia dominante de investigadores formados y / o insertos institucionalmente en la UBA en las comisiones evaluadoras.

Veamos brevemente cómo se han conformado las comisiones asesoras del CONICET entre 2005 y 2015, integradas mayoritariamente por investigadores del organismo: 2.431 de un total de 2.732 evaluadores. Un $56 \%$ son hombres, la gran mayoría pertenece a tres categorías independiente, principal y superior - activos o jubilados ${ }^{8}$ - y sólo un $11 \%$ son docentes universitarios Categorías I-II, no pertenecientes a la carrera del CONICET $(301 / 2.732)^{9}$. La presencia de una formación académica en la UBA pesa considerablemente, pues alcanza el $41 \%$ del total de investigadores que componen las comisiones durante este período $(994 / 2.431)^{10}$. Muchos de los que se doctoraron en la UBA hicieron una maestría en el exterior y frecuentemente tuvieron directores de tesis extranjeros. Prácticamente todos realizaron una residencia de larga duración en el exterior. Gran parte de ellos son docentes de esa institución.

Este universo de evaluadores tiene una morfología parecida a la que el organismo tenía durante la década de 1990, es decir una pirámide envejecida de investigadores consagrados, mayores de 45 años, en la que es interesante notar una incidencia más relevante de la titulación en el exterior. Del total de investigadores e investigadoras del CONICET que componen estos comités evaluadores, el 27\% (647/2.431) obtuvieron su título de doctorado en otro país. Se trata en definitiva de los formadores de la pirámide rejuvenecida actual, ésta última con altísima proporción de doctorado en Argentina como analizamos más arriba. Si consideramos ahora que la titulación en el exterior y la graduación en la UBA favorecen estilos de producción internacionalizados, es relevante observar que juntas, estas trayectorias de formación representan un $68 \%$ del total 
de los integrantes de las comisiones asesoras en los últimos 10 años. Un porcentaje menor de este universo de evaluadores realizó su formación doctoral en La Plata, $13 \%$ del total $(337 / 2.431)$ y un $8 \%$ en Córdoba $(206 / 2.431)$. Eso implica que un $62 \%$ del total de evaluadores fueron formados por tres universidades argentinas (no casualmente las más antiguas y prestigiosas). Si afinamos aun más la mirada y tomamos solo a los miembros con cinco o más participaciones en comisión en el período vemos que más de la mitad fueron formados en la UBA. En particular, si analizamos los miembros de la Junta Calificadora de Méritos, que tienen un papel decisivo en el proceso de evaluación, la preeminencia de trayectorias de formación en UBA alcanza el $80 \%$.

La relevancia que adquiere la UBA en la composición de las elites académicas en Argentina muestra que el principio de diferenciación entre Arieles y Calibanes no se expresa en una separación dualista entre el CONICET y las universidades en general. Si bien los perfiles típicos de Ariel por lo general corresponden a investigadores e investigadoras del CONICET, sus formaciones están ligadas al anillo más antiguo del sistema universitario (UBA, UNLP y UNC) donde el prestigio internacionalmente reconocido tiene una larga tradición y la mundialización universitaria se impuso tempranamente. En todas las áreas científicas existen académicos célebres de la UBA que circularon e internacionalizaron los institutos que dirigieron en distintas épocas (Prego y Vallejos, 2010). Además, los cinco premios Nobel argentinos fueron todos docentes de la UBA (4/5 se graduaron, además, en UBA, excepto Adolfo Pérez Esquivel que se graduó en la UNLP pero luego ejerció la docencia en la Facultad de Ciencias Sociales de UBA).

Si ahora nos centramos en los 4.266 docentes-investigadores que tienen categoría I-II pero no son investigadores del CONICET, veremos que la proporción de profesores con lugar de trabajo en la UBA es del 10\%, mucho más baja que en la morfología del CONICET. A diferencia del sistema de evaluación del CONICET, atado fuertemente a la publicación internacional en revistas indexadas, en las universidades nacionales se prioriza la docencia y los proyectos de investigación subsidiados por la propia institución tienen montos exiguos. Como señala Vasen (2013), la pauta de distribución de fondos para investigación en las universidades puede caracterizarse como "solidaria" y los sistemas de becas se orientan más al grado que al posgrado. Un docente-investigador que no pertenece al CONICET, aunque tenga dedicación exclusiva a la docencia, dedica escaso tiempo a estos proyectos que tienen mínimas expecta- 
tivas y poco pueden exigir resultados publicables. El monto del incentivo que se paga a los docentes-investigadores quedó estacionado y constituye hoy más un gesto simbólico que un estímulo a la investigación. Sin embargo, en las últimas décadas aumentó sistemáticamente la cantidad de docentes que participan del PIDI, y las categorías de este programa son objeto de interés, como lo muestra la masiva inclinación de los docentes a solicitar su categorización en 2015.

Hasta el momento, ni el PIDI ni las evaluaciones externas universitarias han impuesto las publicaciones en circuitos mainstream como determinantes y se desarrollan procesos de evaluación relativamente autónomos por región. La resolución general que reglamenta las pautas de evaluación establece que las publicaciones científicas "con referato/arbitraje" tienen mayor puntaje que las sin referato y sólo incluye una salvedad para aspirar a las dos categorías superiores: que dichas publicaciones sean "preferentemente indexadas" (Res. ME no 1543/2014, Art. 18-e). Un profesor o una profesora sin doctorado y con una trayectoria de docencia, antes que de investigación, puede obtener el puntaje correspondiente a la categoría máxima (I) por cuanto los antecedentes docentes, la producción en docencia, la transferencia y la gestión tienen un peso importante (Res. ME no 3564/2014) ${ }^{11}$. Muchos profesores y profesoras que alcanzaron la categoría I o II quince años atrás pueden retenerla sin presentarse durante dos procesos de categorización, y quienes obtuvieron categoría I en dos instancias consecutivas mantienen esa categoría en forma vitalicia.

Así las cosas, es comprensible que los perfiles estilo Calibán vean a la cultura evaluativa del CONICET como una amenaza a sus posibilidades de subsistir en el sistema. Por lo tanto, han tenido (y tienen) muchas razones para maldecir a Próspero. Y han tenido la posibilidad real de hacerlo: pueden publicar sólo en español, en revistas no indexadas o sin factor de impacto en los circuitos de corriente principal. Lo que no sabemos es cuánto tiempo podrán seguir haciéndolo, dado el nuevo contexto político argentino, porque la autonomía universitaria está en juego y los criterios "internacionales" de evaluación irán imponiéndose lentamente también en las universidades.

\section{EL ESTILO DE ARIEL Y LA CONSAGRACIÓN EN EL CONICET: LAS CINCO "PUBLICACIONES MÁS RELEVANTES DE LA CARRERA"}

La literatura disponible muestra que la lengua más poderosa a nivel global es el inglés, y que las otras lenguas tienen una participación pro- 
gresivamente subalterna en el movimiento internacional de las ideas (De Swaan, 2001; Hagége, 2002; Heilbron, 2008; Casanova, 2015). Eso implica que los intercambios lingüísticos en el mundo académico son asimétricos porque existe una diversa valorización social de las lenguas y un acceso desigual a la capacitación que la escritura en inglés científico implica (Chardenet, 2012; Gerhards, 2014). Sin embargo, en estudios previos hemos sostenido que, para explicar la creciente segmentación de los circuitos de consagración en el sistema académico mundial y la posición de los científicos periféricos, observar la supremacía del inglés no es suficiente. Es necesario poner en juego un principio triple de jerarquización que actúa separando regiones académicas desiguales mediante una combinación entre la lengua de publicación, la afiliación institucional y la disciplina (Beigel, 2014a, 2014b). De hecho, como decíamos antes, el capital cultural y en particular el capital lingüístico adquirido en la socialización familiar, no garantizan por sí mismos un habitus internacional ni la publicación en circuitos de corriente principal. En la construcción de esta elite internacionalizada, la disciplina se presenta como un factor diferenciador y juegan un papel fundamental los saberes institucionales, especialmente aquellos tipificados por grupos prestigiosos como los de la Universidad de Buenos Aires, que inciden fuertemente en los procesos de evaluación y en la morfología del CONICET.

En Beigel (2014b) hemos mostrado que en las evaluaciones de ingreso al CONICET se identifica la calidad de la revista con la indexación y que la publicación internacional es un elemento excluyente para determinar si un candidato o candidata puede ser considerado un investigador. En lo que sigue, analizaremos nuestra base de datos de publicaciones de los investigadores e investigadoras del CONICET que se conforma con una sub-población de 4.842 agentes que se presentaron a promoción al menos una vez entre 2007 y 2013, y que debieron elegir las "5 publicaciones más relevantes de su carrera"12. Esta sub-población está bastante equilibrada porque incluye más del $50 \%$ de los efectivos que, en términos de disciplina, edad y jerarquía en la Carrera de Investigación Científica (CIC), existen para la totalidad del organismo. Inclusive de la generación más joven (31 a 44 años), que son muy numerosos dado el rejuvenecimiento reciente de la pirámide, la base incluye 1.859 del total de 3.650 que tiene el organismo. Analizada por área científica, se constituye con más del 50\% de investigadores e investigadoras de cada una de las cuatro áreas definidas por el $\mathrm{CONICET}^{13}$. Al examinarla por categoría, en cambio, aparecen relati- 
vamente sub-representados los y las investigadores asistentes que en gran parte pueden aún no estar habilitados a presentarse a promoción. De los 4.842 agentes que componen esta base de datos, el 29,7\% (1.441) se doctoraron en la UBA, una proporción también semejante al universo total del organismo. Un 51\% son mujeres y el 36,5\% declara conocimientos de inglés, mayormente avanzado, pero es una información que buena parte de los investigadores no ha completado en la base SIGEVA ${ }^{14}$.

En el CONICET existen actualmente cinco posiciones con jerarquía ascendente en la CIC: asistente, adjunto, independiente, principal y superior. La posición más baja (asistente) se reserva para investigadores jóvenes, de entre 30 y 35 años de edad; adjunto para 36-40 años; independiente, 41-45 años; principal, de 46-50 años. La posición más alta, investigador superior, se obtiene mediante concurso especial. Las convocatorias de promoción se efectúan una vez al año y son voluntarias. Es de suponer que los investigadores jóvenes que no se han presentado, no cumplen aún el requisito de permanencia en la categoría inicial y que los más viejos que no la han solicitado no tienen suficientes publicaciones para solicitarla o están menos atados a la competitividad por el ascenso.

Es importante destacar que estas cinco "producciones más relevantes" son las que el propio investigador elige, con la expectativa de que sean valoradas por las comisiones evaluadoras, con lo cual, dicen mucho acerca de los consensos que se van construyendo sobre los criterios de evaluación en el organismo. Pero en muchos casos, particularmente en las Ciencias Sociales y Humanas (CSYH), el estilo de estas publicaciones no refleja el resto de las publicaciones del investigador en su currículum. Es decir, para solicitar la promoción seleccionan por lo general artículos antes que libros, publicaciones indexadas y en inglés antes que revistas argentinas, mientras que la observación de las trayectorias completas muestra un patrón menos atado a ese estilo internacionalizado que predomina en el organismo.

Sumando las cinco producciones más relevantes que cada uno de ellos declara, tenemos un total de 23.852 producciones que nos permiten observar el título del trabajo, el tipo de producción (libro, capítulo de libro, artículo, acta de congreso, informe técnico) y el idioma. Como resultado de una operación general de promedio de la cantidad de publicaciones en inglés, en español, y en otros idiomas para cada in- 
vestigador, observamos que el perfil en general de esta sub-población es muy homogéneo y arielesco. El promedio general de producciones en inglés llega a 4,02 sobre 5 . Si aislamos los hombres, este promedio sube a 4,13, mientras que para las mujeres el promedio es de 3,91. Analizada por rango de edad se observa un descenso en la generación mayor (65-85 años), pero de una dimensión poco relevante, lo que comprueba que la escritura en inglés es un fenómeno ya instalado hace varias décadas en Argentina. Una dispersión levemente diferente es observada en el tipo de producción, que exhibe una presencia de libros y capítulos de libros en las generaciones mayores. El hecho de que 4,4 sobre 5 sean artículos para el grupo de 31-44 años es una evidencia de que el estilo paper se impone en las generaciones más jóvenes de todas las áreas, al momento de seleccionar las cinco producciones más relevantes de su carrera.

Mientras que para las ciencias exactas y naturales el estilo paper se impuso hace mucho tiempo, en las CSYH el libro mantiene una importante vigencia. Lamentablemente no hay estudios regionales ni nacionales sobre la publicación de libros científicos, incluso escasea esta información en los informes mundiales de la ciencia. Los pocos estudios disponibles tienen información parcial debido a las dificultades de fondo que tienen las estadísticas tradicionalmente medidas por UNESCO (Statistical Yearbooks, Index Translationum). Analizada por área científica, nuestra base de datos arroja interesantes

\section{Gráfico 1}

Producciones Más Relevantes de la Carrera por Edad N=23.852 (2015). Promedios por Lengua y Estilo de Producción (sobre 5) ${ }^{15}$

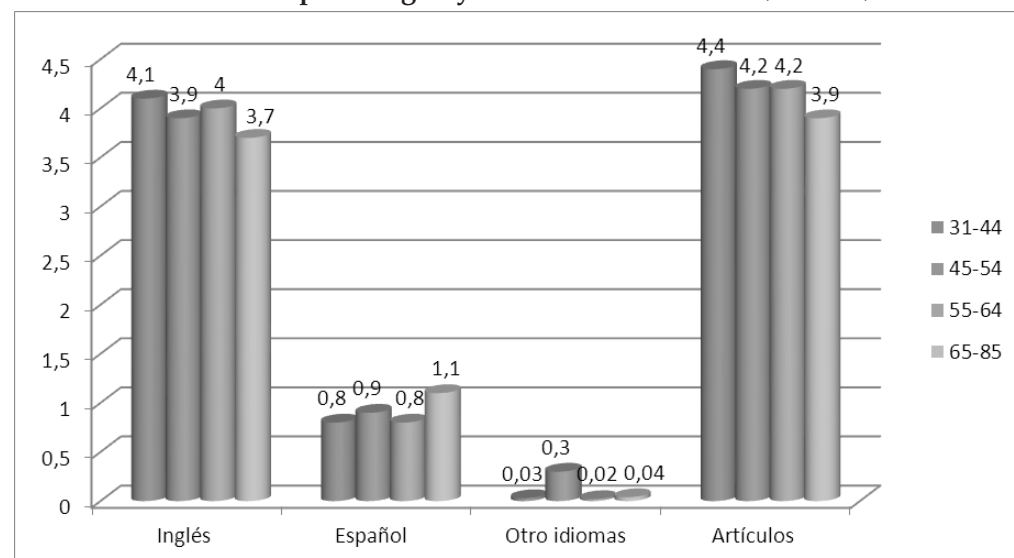

Fuente: Elaboración propia. 
Gráfico 2

Producciones Más Relevantes de la Carrera por Área Científica n=23.852 (2015).

Promedios por Lengua y Estilo de Producción (sobre 5)

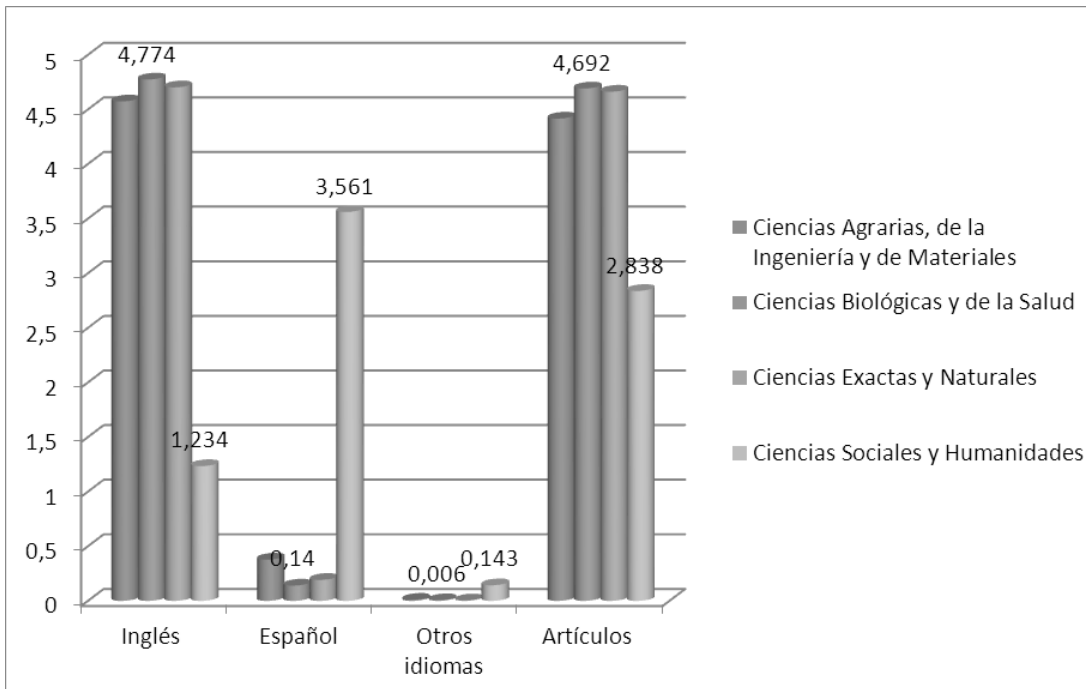

Fuente: Elaboración propia.

diferencias en relación con el predominio de libro/artículo por área, aunque el promedio de artículos para los investigadores e investigadoras de las CSYH resulta bastante alto: 2,838. En cuanto al predominio del idioma, la observación por áreas muestra la abrumadora mayoría de publicaciones en inglés en las ciencias "duras", alcanzando promedios de 4,77 mientras que en las CSYH las publicaciones en inglés representan 1,23 sobre 5 .

No cabe duda de que la universalización de una lengua y un estilo de producción se manifiestan en un sistema de publicaciones que recompensa el artículo frente al libro. Pero la circulación del conocimiento en estos dos soportes no está totalmente divorciada: hay una concentración visible en el mercado de la edición científica. Larivière, Haustein y Mongeon (2015) analizaron 45 millones de documentos indexados en ISI-Web of Science entre 1973 y 2013, demostrando que tanto en las ciencias exactas y naturales como en las CSYH, cuatro editoriales incrementaron sostenidamente su parte de la producción publicada en revistas. Este oligopolio, formado por Reed-Elsevier, Wiley-Blackwell, Springer, Taylor \& Francis y SAGE maneja más del 50\% de todos los artículos científicos publicados en ese circuito en 2013. En lo que respecta 
Científicos Periféricos, entre Ariel y Calibán. Saberes Institucionales y Circuitos...

Gráfico 3

Producciones Más Relevantes de los Investigadores de Ciencias Sociales y Humanas, por Edad $n=4.691$ (2015).

Promedios por Lengua y Estilo de Producción (sobre 5)

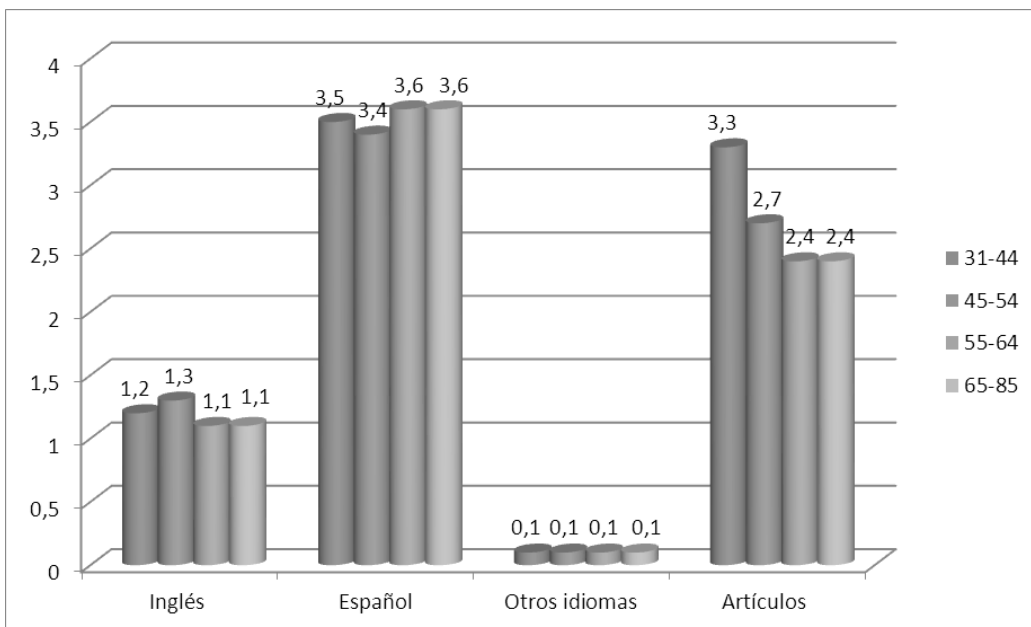

Fuente: Elaboración propia.

a los libros, estas mismas editoriales concentran buena parte de la publicación de libros en inglés en todas las áreas.

La homogeneidad del tipo de producción (artículo) e idioma (inglés) que se presenta entre los y las investigadores de las ciencias exactas, naturales, biológicas, agrarias e ingenierías no permite diferenciar perfiles por edad o disciplina. Conviene entonces ahora observar a las CSYH donde sí podemos diferenciar perfiles generacionales en relación con el tipo de producción, aunque no con respecto al idioma porque los valores del predominio del inglés son parecidos en todas las generaciones. El estudio de Molteni y Zulueta (2002) muestra que en los años de 1990 los cientistas sociales argentinos que publicaban en inglés lo hacían en general en revistas de psicología, economía, literatura y estudios latinoamericanos. Esto se sigue verificando aquí con el agregado de una presencia fuerte de la ciencia política en medios anglosajones.

Es interesante destacar que los 941 investigadores de CSYH que forman parte de esta subpoblación en gran parte tienen lugar de trabajo en una universidad nacional o unidades ejecutoras conjuntas CONICET-Universidades Nacionales, siendo la UBA central. El 33,7\% 
se doctoró en la UBA, un poco por encima del promedio de todo el universo, y el 43,5\% obtuvo su título de grado en esa institución, bastante más alto que el conjunto. El 56\% del total en esta área son mujeres y el promedio de publicaciones en inglés para ellas es de 1,14. Aislados los hombres, el promedio es levemente mayor: 1,35 . Si comparamos algunas disciplinas típicamente feminizadas, los promedios muestran que la variable género no es determinante. En Literatura el promedio para las mujeres baja a 0,80 pero en Psicología sube a $1,72^{16}$.

De los 335 que pertenecen al rango más joven (31-44) que ingresó a CIC entre 2004-2012, un 38,3\% se doctoró en la UBA y sólo 5/335 no tienen cargo docente en una universidad nacional. En contraste con la generación mayor, los investigadores entre 65-85 años, un 30\% no tiene cargo docente universitario, el 23\% hizo su doctorado en el exterior y un 15\% no tiene doctorado. Los investigadores adjuntos o independientes que se inscriben en el grupo etario de los 45-54 años tienen una tendencia levemente más alta a las publicaciones en inglés, en gran medida por el peso que este factor adquirió en las difíciles competencias de ingreso que tuvieron que enfrentar entre 1993 y 2002. Aunque la presencia de otros idiomas en las publicaciones es mínima, podemos mencionar que son, en orden de frecuencia: francés, portugués, alemán e italiano.

Con respecto a los circuitos de circulación, en Beigel (2014a) hemos observado que al menos cuatro circuitos atraviesan el proceso de construcción del prestigio científico en la periferia y que nos permiten clasificar las publicaciones de los investigadores ${ }^{17}$ :

a) el circuito de corriente principal ceñido a las mediciones de factor de impacto y rankings de revistas (WoS Thomson \& Reuters hoy Clarivate, SCOPUS), representa un circuito de consagración "universalmente" aceptado aunque con un alcance limitado en términos de circulación efectiva/lectores, por su carácter cerrado (con onerosas suscripciones) y un alcance limitado también en cuanto a cobertura de revistas de calidad de países en desarrollo;

b) los circuitos transnacionales, en formato de acceso abierto, que incluyen variados repositorios e indexadores como Google Scholar, DOAJ, con desiguales efectos en términos de reconocimiento para quienes son evaluados con indicadores surgidos de estos indexadores; 
c) los circuitos regionales también en acceso abierto, que en nuestra región incluye repositorios como SciELO, Latindex y Redalyc, con efectos de consagración académica básicamente para las CSYH;

d) los circuitos locales se forman con revistas que no están indexadas en ningún repositorio y por lo general, se publican únicamente en papel, con recompensas para los docentes universitarios. Existen sistemas nacionales de clasificación nacionales que tienen diverso "apego" a normativas y criterios de los sistemas mainstream o regionales. Núcleo Básico de Revistas CAICYT/CONICET en Argentina, Publindex en Colombia, QUALIS/CAPES en Brasil, CONACYT en México. Pero su validez nacional y su reconocimiento en las evaluaciones debe ser analizado en cada país.

Para examinar los diferentes circuitos de circulación de las "producciónes mas relevantes" de los y las investigadores del CONICET, construimos una muestra intencional considerando cuotas, que contiene un 30\% de la cantidad de investigadores de cada área científica y de cada rango etario de la población total que se presentaron a promoción. Se trata de 1.418 individuos que se presentaron a promoción y un total de 7.071 producciones publicadas de las que disponemos información completa sobre título de la revista, editorial, país de edición, editorial y año de la publicación (además del titulo del artículo o libro, el tipo y el idioma que contiene la base de datos mayor). Para poder observar la circulación de estas publicaciones procedimos a promediar la cantidad de publicaciones que transitan cada circuito.

Aunque las producciones en estilo libro y capítulos de libro no sean muchas, procedimos a clasificar las editoriales también por circuito, tratando como parte de la corriente principal las editoriales que Lariviére, Haustein y Mongeon (2015) consideran como los oligopolios de la edición científica, además de Cambridge, Oxford y California Press. En el circuito transnacional incluimos todas las editoriales no-latinoamericanas: Universidades estadounidenses, españolas y alemanas, sociedades académicas europeas, norteamericanas, de Asia o Africa. En el circuito regional incluimos las editoriales con distribución latinoamericana, como CLACSO, SIGLO XXI, Fondo de Cultura Económica, Sudamericana. Las editoriales de distribución nacional o provincial fueron consideradas en el circuito local. Como puede verse en el gráfico 4, el $83 \%$ de las producciones totales circula por el circuito mainstream. Del total de producciones que no transitan por circuitos dominantes, el 76\% corresponde a investigadores de CSYH y buena 


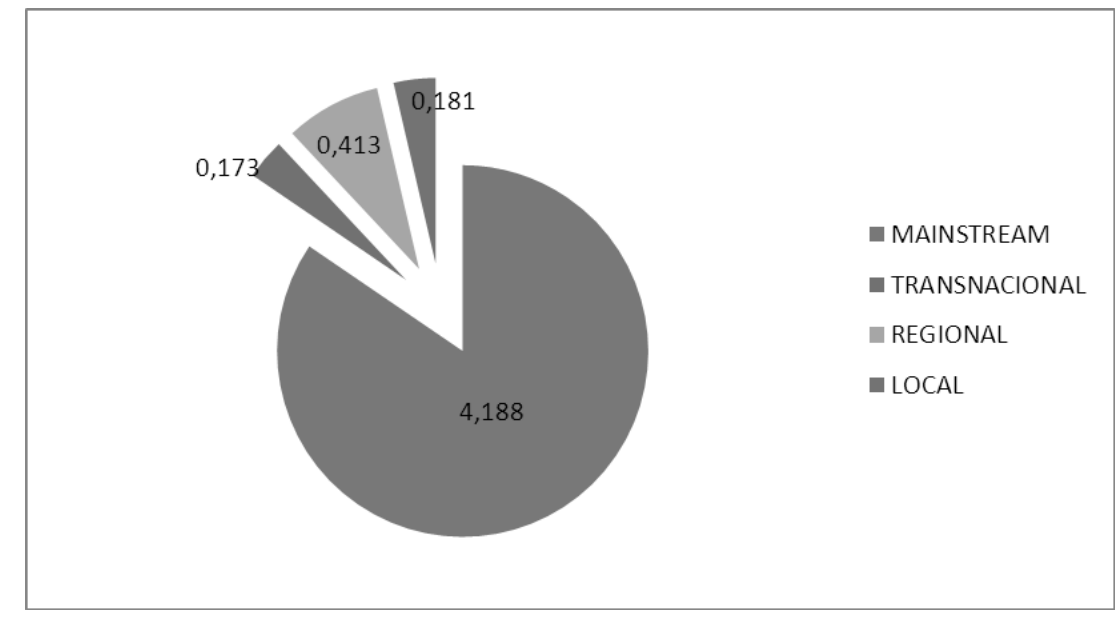

Fuente: Elaboración propia.

parte del resto son convenios, registros de propiedad o ponencias en congresos internacionales.

En Beigel (2014b) hemos mostrado que en las CSYH predomina también el patrón general de reemplazo de la evaluación de la calidad de los artículos por la indexación, aunque en este caso se observa la valoración de los repositorios latinoamericanos y son más escasas las publicaciones en circuitos mainstream. Latindex y los sistemas transnacionales como DOAJ y Dial-net son los repositorios más recurrentes de las publicaciones registradas en esta área científica. Resulta interesante analizar las diferencias observables entre estas constataciones y los resultados del trabajo de Gantman (2011) que analizó 414 currículum vitae de investigadores e investigadoras de cuatro disciplinas, economía, sociología, psicología y ciencias políticas. En su estudio detectó un predominio de la producción en revistas locales y una baja participación en revistas indexadas en ISI/Web of Science. Allí donde las publicaciones internacionales o en inglés eran significativas correspondía a investigadores que habían realizado sus doctorados en el exterior (2011:418-419). Efectivamente, estas disciplinas tienen una historia más reciente y más interrumpida de institucionalización, por lo que hay tradiciones menos consolidadas de internacionalización de equipos y redes. Pero en estos últimos años la base demográfica del CONICET se rejuveneció y estas generaciones de investigadores asis- 


\section{Gráfico $5^{20}$}

Promedio de Publicaciones Relevantes por País de Edición, n=7.071 (2015)

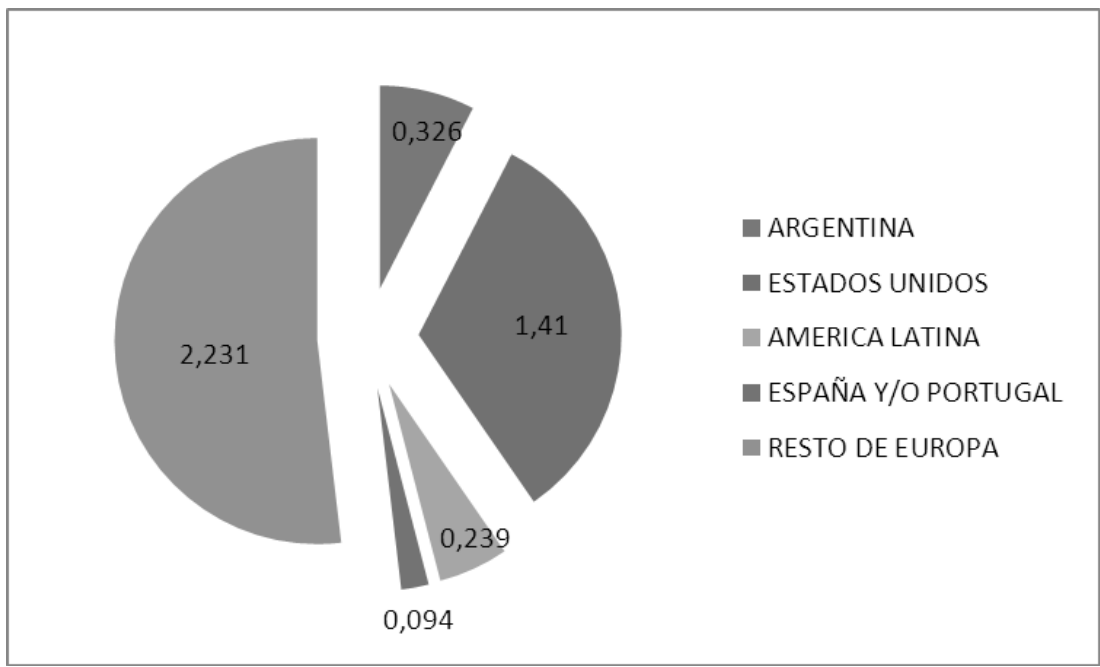

Fuente: Elaboración propia.

tentes que ingresaron al organismo lo hicieron sobre la base de una cultura evaluativa cada vez más exigente en términos de publicaciones internacionales. Es por ello que el circuito regional se convirtió en el espacio privilegiado de circulación de estos nuevos agentes.

Esto se ve con particular claridad al relacionar las cinco producciones más relevantes en relación con el país de edición. Un dato significativo que arroja el Gráfico 5 tiene que ver con la internacionalización de las publicaciones. En forma global, las publicaciones en Argentina no alcanzan el 7\% y gran parte de éstas corresponden a las CSYH, aunque también hay publicaciones en actas de congresos argentinos en las otras áreas. La tendencia actual en estas disciplinas es la publicación en español o portugués en revistas latinoamericanas indexadas principalmente en Latindex Catálogo.

Como advertimos, al comienzo, todo esto no significa que este estilo de publicación que se observa en las "publicaciones más relevantes" sea representativo de la producción completa de los investigadores, sino más bien del perfil de Ariel que actualmente orienta la cultura evaluativa del CONICET. Para analizar los patrones de construcción de las carreras académicas es necesario observar de forma cuantitativa y cualitativa todas las publicaciones. Es decir, son dos corpus distintos: el 
trabajo sobre los currículos permite observar las trayectorias, mientras que las " 5 producciones más relevantes" constituyen una selección que esos investigadores e investigadoras hacen en función de las publicaciones que suponen que serán mejor evaluadas. Por lo tanto, el presente artículo permite dilucidar las creencias y consensos que se han extendido en el CONICET en torno de lo que significa una producción científica prestigiosa, pero no implica que esas creencias dominen con igual fuerza en las trayectorias de estos científicos. Con seguridad, los y las investigadores con el estilo de Ariel creen que es necesario publicar en el circuito mainstream para ascender en el CONICET, pero saben que pueden ser en parte Calibán, para intervenir en la agenda local de discusión y contribuir a la generación de soluciones para problemas socialmente relevantes.

\section{CONSIDERACIONES FINALES}

Más allá de la utilidad analítica de distinguir dos perfiles de producción opuestos, vimos que el dominio de Arieles y Calibanes no ocurre en islas separadas, al estilo dualista: una isla cosmopolita que se construye a imagen y semejanza de los "centros de excelencia" del sistema académico mundial y otra isla nacionalista que mira hacia adentro en los claustros de las universidades. La distribución de la consagración en el mundo científico argentino es un proceso complejo en el que co-existen diversas culturas evaluativas, que están relacionadas conflictivamente en la estructura del campo científico-universitario. El CONICET ha crecido geométricamente en todo el país, con lo cual la cultura evaluativa internacionalizada aparece (en mayor o menor medida) en todo el campo. Sin embargo, los perfiles del estilo de Ariel se concentran en las universidades más prestigiosas, donde reinan sobre un importante número de súbditos aspirantes a la prosperidad.

La internacionalización actual de las elites académicas argentinas no es un resultado del capital lingüístico heredado o de la formación de posgrado en el exterior, sino más bien de la combinación entre un habitus internacional (consolidado históricamente en el CONICET y las universidades más prestigiosas) y unos saberes institucionales específicos que surgen en el contexto de equipos de investigación de larga trayectoria. Un conjunto de factores exógenos y la propia historia del campo estimularon una modalidad de circulación de los investigadores del CONICET que reforzó la disposición a aceptar normas provenientes de los "centros de excelencia" en desmedro de las normas locales, que 
se consideraban endogámicas o de bajo nivel. La arraigada tradición de la publicación en colaboración internacional en las ciencias "duras" fue modelizando los saberes institucionales requeridos para el ingreso y la promoción en el CONICET. Y estos se reprodujeron en la formación en doctorados locales que entrenaban a los alumnos en la escritura de papers en inglés para revistas estilo ISI-WoS, estimulando tempranamente la participación en redes y proyectos transnacionales. Hemos argumentado que este capital institucional cumple, así, el papel de un capital social.

La UBA tiene un papel dominante en la configuración de este perfil, pero no participa exclusivamente de la formación de una elite internacionalizada. Ante ojos propios y ajenos, esta universidad tiene la envergadura y la entidad de un "sistema universitario en sí mismo", por lo cual presenta asimetrías intra-institucionales propias. Por el gigantismo de su matrícula tiene la capacidad de movilización estudiantil más grande del país y pudo mantenerse hasta la actualidad en desacato respecto de la Ley de Educación Superior, resistiendo la adaptación de sus estatutos en los años 1990. Es una universidad con una actividad política intensa y centrífuga. Por eso, reproduce Arieles, pero también Calibanes y perfiles intermedios. Recientemente fue noticia que la UBA estaba entre las cincuenta mejores universidades del mundo en la medición del Ranking Mundial de Universidades por Temática QS 2015 y alcanzó una posición relevante entre las universidades latinoamericanas en el ranking Shanghái 2016. En definitiva, la masividad de la universidad más grande del país no impide que sea, a la vez, la institución rectora de las elites académicas en Argentina.

Desde el punto de vista disciplinar, hemos visto que los estilos de producción y circulación en el CONICET son bastante homogéneos, diferenciándose únicamente el área de las ciencias sociales y humanas. Esto no sólo obedece al papel subordinado de estas disciplinas en el sistema académico mundial sino también a la propia historia de las ciencias sociales en el campo científico-universitario argentino, ya que en la última dictadura militar padecieron cárcel, persecuciones, exilios, y sus escuelas/carreras fueron clausuradas. El crecimiento del CONICET en esta última década logró compensar y equilibrar las áreas científicas y, como resultado, la composición etaria de las CSYH es la más joven, siendo el $70 \%$ de los investigadores adjuntos y asistentes. La publicación internacional y la indexación tienen un peso relevante en estas disciplinas, aunque se observa un perfil más bien orien- 
tado al reconocimiento académico en el circuito regional (latinoamericano).

No deja de ser llamativo el valor del estilo ISI-WoS en una agencia pública de investigación como el CONICET que, a diferencia de países como Chile, no recompensa directamente las publicaciones en revistas de corriente principal mediante incentivos salariales. La indexación no es un dato que se incluya en los currículos disponibles en la base SIGEVA, pero son las comisiones evaluadoras las que recurren a ésta para establecer el orden de méritos en cada disciplina. Por otra parte, el CONICET ha tenido una política más bien "nacionalista" en la expansión de los recursos materiales y humanos (becas sólo para doctorados en Argentina, repatriación). Desde el Ministerio de Ciencia y Tecnología se desarrollaron políticas tendientes a la conexión entre la investigación básica, la transferencia y las necesidades productivas, una meta que entraba en tensión con esta cultura evaluativa internacionalizada y la tendencia academicista de los patrones de construcción de carreras en el organismo.

A pesar del peso creciente de la dependencia respecto de los criterios "internacionales" en la cultura evaluativa del CONICET, es justo aclarar que publicar en inglés y en el circuito mainstream no implica que sus investigadores sean objetos de una suerte de colonialidad científica. Los campos periféricos no son meros objetos de conquista o resistencia pasiva, y la heteronomía y la autonomía conviven en la medida en que la periferialidad se ha complejizado crecientemente. América Latina es la región en la que más ha crecido el movimiento de acceso abierto y los circuitos alternativos (Babini y Machin-Mastromatteo, 2015). En Argentina tenemos tradiciones académicas centenarias y una producción intelectual autónoma, en la que no es viable pensar en términos de aculturación. Esto se refleja en una ciencia pública consolidada, con una fuerte industria editorial y una rica historia de publicaciones periódicas. Nuestra producción de conocimiento ofrece conceptualizaciones propias, nuevas ideas y no es mero recolector de datos para los centros de excelencia o reproductor de agendas foráneas, como comúnmente se plantea desde la perspectiva de la "colonialidad del saber" (Beigel, 2016).

Desde una definición operativa de dependencia académica, podemos decir que la internacionalización heterónoma se observa en la segmentación de circuitos y en el desplazamiento de la evaluación de la cali- 
dad por la creencia en un sistema de indexación elaborado sin la participación de los científicos periféricos. Y esto indica la necesidad de una reflexión seria, por parte del organismo y de la propia comunidad académica, acerca de la pertinencia y sentido de los criterios de evaluación que se vienen aplicando. No se trata de "desconectarse" del sistema de publicaciones ni tampoco de desconocer la pertinencia de la evaluación de pares, sino de determinar libremente los criterios de evaluación de la calidad, atendiendo a las exigencias de la ciencia a nivel mundial, pero también a las necesidades de la agenda nacional y/o local de investigación.

La historia del campo científico-universitario argentino explica que existan poderosos reinos de Calibanes que resisten la mundialización académica y prósperos reinos de Arieles que resisten el corporativismo universitario. ¿Podrá Ariel volver su mirada sobre la calidad de la producción científica antes que confiar ciegamente en la indexación de las revistas, promoviendo una orientación hacia los problemas socialmente relevantes para su comunidad? ¿Podrá Calibán salir de su endogamia para dialogar con otros Calibanes en circuitos abiertos donde prime la ciencia como bien común? No es necesario rendirse a las reglas de Próspero para ampliar los horizontes de la circulación. Y la ciencia argentina tiene mucho por ganar si estimula programas de difusión, políticas de traducción y prácticas evaluativas que permitan "internacionalizar" un poco la endogamia y "nacionalizar" otro tanto la exogamia. Lamentablemente, la viabilidad de llevar esto adelante en el contexto actual es incierta debido a la victoria electoral de Mauricio Macri a finales de 2015, cuya orientación neoliberal permite suponer que devendrá un proceso de mercantilización de la ciencia pública argentina. En el camino de defender los logros alcanzados y reflexionar sobre las deudas pendientes, vamos andando Arieles y Calibanes.

(Recebido para publicação 9 de outubro de 2015) (Aprovado para publicação 2 de abril de 2016) 


\section{NOTAS}

1. El CONICET otorga becas para hacer doctorados exclusivamente en Argentina. Las becas doctorales externas fueron disminuyendo paulatinamente desde $2000 \mathrm{y}$ fueron eliminadas en 2007.

2. Agradezco al Área de Información Estratégica en Recursos Humanos del CONICET y especialmente a Isabel Miranda, Hernán Beorlegui y Esteban Moro.

3. Analizado por quintiles de ingreso, para 2013 , en el nivel primario, el $85,5 \%$ de los estudiantes del quintil más pobre asistía a escuelas públicas, mientras en los quintiles más ricos (4 y 5) asistía el 48,8\% y el 31,3\% respectivamente. En el quintil más pobre el $87,6 \%$ asiste a escuelas secundarias públicas mientras en los quintiles 4 y 5 el porcentaje es de 53,6\% y 45,8\% respectivamente (SEDLAC, 2015). Cabe aclarar que en el nivel secundario aumenta la matrícula pública en los sectores altos debido al peso de las escuelas universitarias prestigiosas, es decir aquellas que dependen de universidades nacionales y que existen en las ciudades más importantes del país.

4. Un acontecimiento público relevante en la memoria de los investigadores del CONICET fue el desprecio que el ministro de economía, Domingo F. Cavallo, propinó a la investigadora y socióloga Susana Torrado (que había criticado la tasa de desocupación advirtiendo sobre las consecuencias del ajuste neoliberal) diciéndole "esa mujer! por qué no se va a lavar los platos".

5. Una de las universidades del interior, la Universidad Nacional de Cuyo, modificó la ordenanza de concursos efectivos en 2010 para valorar la trayectoria docente en la propia institución. La distribución de los antecedentes en la grilla de evaluación otorga 600 / 1000 puntos a los antecedentes y 400 / 1000 a la clase pública. Entre los antecedentes prima la trayectoria docente (240 puntos), los antecedentes en gestión institucional, extensión universitaria y actividad profesional (60 puntos cada uno respectivamente) totalizando estos cuatro aspectos 420/1000. Los títulos valen 80 puntos, pero el título de grado no puede ser valorado en menos del $50 \%$ del puntaje correspondiente a este ítem. Mientras, los antecedentes de investigación tienen un total máximo de 100/1000 puntos. Cfr. Ordenanza del Consejo Superior no23 (2010).

6. El lugar de trabajo y el cargo docente fueron proporcionados por el sistema administrativo del CONICET. Es importante aclarar que 830 de esos cargos docentes son adscriptos ad-honorem o ayudantes.

7. De un total de 562 investigadores/as no fue posible relevar la institución del doctorado. Por lo general se trata de la generación mayor a 60 años sin doctorado, formados en un período en el que aún no se extendía la obligatoriedad de ese nivel de estudios.

8. Los y las investigadores adjuntos pueden ser convocados solo en las comisiones asesoras para becas.

9. La composición de las comisiones asesoras que analizamos aquí se basa en un listado proporcionado por el CONICET, a partir de una solicitud nuestra, con los/las integrantes de todas las comisiones asesoras del organismo desde 2005 hasta 2015, incluyendo para cada participación la fecha, el tipo de comisión, y la categoría del investigador. Luego construimos una base de datos incluyendo las participaciones acumuladas, la formación de grado, doctorado, cargo docente y lugar de trabajo de cada integrante de comisión. En este trabajo nos limitamos a describir la formación de estos evaluadores, un análisis más profundo se encuentra en elaboración. 
10. Nos referimos en general al título doctoral pero hemos sumado también aquellos casos de investigadores sin título doctoral (con mérito equivalente) que se graduaron en UBA y mayormente son, también docentes de esa institución.

11. Existen disputas entre la valoración de los antecedentes docentes y de gestión frente a la titulación doctoral, las direcciones de tesis y publicaciones para acceder a las categorías más altas, pero la reglamentación ha cambiado poco con el paso del tiempo y no hay estudios sobre las diferencias en la categorización por región. En PIDAAL estamos realizando un estudio con observación participante en la categorización en curso y esperamos que del mismo surja información nueva para diferenciar perfiles.

12. Construimos la base de producciones relevantes a partir de un segundo pedido oficial al sistema SIGEVA-CONICET que fue concedido en junio de 2015, fecha de toda la información ofrecida en esta parte del trabajo.

13. Recientemente el CONICET comenzó a considerar una quinta área de Tecnología y desarrollo social. Sin embargo, la base de datos que analizamos en fines de este trabajo data de diciembre de 2014 cuando aún se preservaba la organización en aquellas cuatro áreas científicas.

14. En PIDAAL existe una investigación doctoral en curso (O. Gallardo) sobre las trayectorias de formación y la internacionalización de los científicos argentinos. Por otra parte, nos encontramos en la implementación de la encuesta de capacidades lingüísticas y habitus internacional en el marco del Proyecto de Investigación Científica y Tecnológica no 2013-1442, financiado por la Agencia Nacional de Promoción Científica y Tecnológica (ANPCYT) y el Proyecto no3/2015 del Núcleo de Estudios e Investigaciones en Educación Superior (NEIES) del Mercosur, como parte de un estudio comparativo entre Argentina, Brasil y Chile.

15. Algunos ingresaron menos de 5 publicaciones más relevantes.

16. El género no parece ser determinante en los estilos de producción, mientras pesan más la disciplina y el capital institucional. Pero conviene aclarar que, aunque el universo de investigadores está bastante equilibrado ( $51 \%$ son mujeres), las asimetrías de género se evidencian en la pirámide jerárquica, siendo más hombres los que ocupan las posiciones superiores de la carrera.

17. La clasificación de los circuitos no contempla sólo las diferencias de indexación sino que se construye sobre diferentes escalas que toman sentido cuando se aplican al estudio empírico de un campo, donde pueden determinarse las segmentaciones según el cruce entre la disciplina, la institución y la lengua de publicación. En otro trabajo hemos analizado el funcionamiento de estos circuitos en las ciencias sociales y humanidades en Argentina. Cfr. Beigel y Sorá (2016).

18. En algunos pocos casos, $4 / 5$ publicaciones pertenecían al circuito mainstream y la quinta publicación era un registro de propiedad, un convenio o una ponencia en un congreso internacional. Para estos casos se consideró 5/5.

19. No se han considerado indexaciones múltiples. Las frecuencias se establecieron sobre la base de una búsqueda jerarquizada en el siguiente orden: ISI-WoS, Scopus, Scielo, Latindex, Doaj, Dial-net, Redalyc. La búsqueda de las revistas en los listados se hizo manualmente porque SIGEVA no solicita ni procesa esta información, a diferencia de los sistemas curriculares como Lattes en Brasil que incluyen la indexación como un dato oficial proveniente de los propios sistemas de indexación (con el altísi- 


\section{Fernanda Beigel}

mo costo que eso tiene). En Argentina, cada comisión evaluadora se ocupa de verificar la indexación de las revistas donde publican los candidatos.

20. El 0,7\% del total no indicaba país de la publicación. Entre las editoriales argentinas tienen mayor frecuencia Prometeo, Edhasa, Prohistoria, Miño y Dávila, Eudeba, y otras editoriales universitarias. Existen unas pocas publicaciones en la Editorial Académica Española (EAE) cuya información del país de edición varía significativamente dado que algunos informan Alemania, España u otros. Por otra parte, existen fundadas dudas sobre su carácter de publicación académica. Tampoco sería adecuado considerarla una publicación local. Por todo ello, nuestra decisión fue no contar las publicaciones en EAE. 


\section{REFERENCIAS}

BABINI, Dominique; MACHIN-MASTROMATTEO, Juan. (2015), "Latin American Science is Meant to Be Open Access: Initiatives and Current Challenges". Information Development, vol. 31, no 5, pp. 477-481.

BASUALDO, Eduardo. (2003), “Notas sobre la Burguesía Nacional, el Capital Extranjero y la Oligarquía Pampeana". Realidad Económica, no 201, pp. 3-12.

BEIGEL, Fernanda. (2006), “Vida, Muerte y Resurrección de las Teorías de la Dependencia", in F. Beigel et al. (orgs.), Crítica y Teoría en el Pensamiento Social Latinoamericano. Buenos Aires, CLACSO, pp. 287-326.

. (2010) "Reflexiones sobre el Uso del Concepto de Campo y acerca de la Elasticidad de la Autonomía en Circuitos Académicos Periféricos", in F. Beigel (org.), Autonomía y Dependencia Académica: Universidad e Investigación Científica en un Circuito Periférico. Chile y Argentina (1950-1980). Buenos Aires, Biblos, pp. 13-44.

. (2013), "The Politics of Academic Autonomy in Latin America", in F. Beigel (ed.), The Politics of Academic Autonomy in Latin America. London, Ashgate, pp.1-28.

. (2014a), "Current Tensions and Trends in the World Scientific System". Current Sociology, vol. 62, no 5, pp. 617-625.

. (2014b), "Publishing from the Periphery: Structural Heterogeneity and Segmented Circuits. The Evaluation of Scientific Publications for Tenure in Argentina's CONICET". Current Sociology, vol. 62, no 5, pp. 743-765.

. (2016), “El Nuevo Carácter de la 'Dependencia Intelectual'”. Cuestiones de Sociología, no 14 .

; BEKERMAN, Fabiana; GALLARDO, Osvaldo. (2016), “Institutional Expansion and Scientific Development in the Periphery. The Structural Heterogeneity of Argentina's Academic Field". Minerva. A Review of Science, Learning and Policy, forthcoming forthcoming.

BEIGEL, Fernanda; SALATINO, Maximiliano. (2015), “Circuitos Segmentados de Consagración Académica: Las Revistas de Ciencias Sociales y Humanas en Argentina". Información, Cultura y Sociedad, no 32, pp.7-32.

BEIGEL, Fernanda; SORÁ, Gustavo. (2016), “Arduous Institutionalization in Argentina: Expansion, Asymmetries and an Uncertain Future", in V. Karady; C. Fleck (eds.), "The Institutionalisation of the Social Sciences. Comparative National Case Studies". Palgrave, MacMillan, forthcoming.

BEIN, Roberto. (2010), “Los Meandros de la Política Lingüística Argentina en Relación con las Lenguas Extranjeras en las Leyes Generales de Educación", in E. Arnoux; R. Bein (eds.), La Regulación Política de las Prácticas Lingüísticas. Buenos Aires, Eudeba.

BEKERMAN, Fabiana. (2013), "Science during Argentina's Military Dictatorship: The Contraction of the Higher Education System and the Expansion of CONICET", in F. Beigel (ed.), The Politics of Academic Autonomy in Latin America. London, Ashgate, pp. 227-247.

BOURDIEU, Pierre. (1979), “Les Trois États du Capital Culturel”. Actes de la Recherche en Sciences Sociales, vol. 30, pp. 3-6. 
Fernanda Beigel

;PASSERON, Jean-Claude. (2003) [1964], Los Herederos. Los Estudiantes y la Cultura. Buenos Aires, Siglo XXI.

CASANOVA, Pascale. (2015), La Langue Mondial. Paris, Seuil.

CHARDENET, Patrick. (2012), Langues et Savoir: Perceptions et Realites du Capital Linguistique dans la Circulation des Connaisances. Coloquio Circulación Internacional del Conocimiento, CINVESTAV-IIESU, México.

CHIROLEU, Adriana. (2012), “Expansion de Oportunidades, Inclusión y Democratización Universitaria", in A. Chiroleu; C. Suasnábar; L. Rovelli (orgs.), Política Universitaria en la Argentina. Buenos Aires, IEC-UNGS, pp. 87-98.

CHARLE, Cristophe. (2009), El Nacimiento de los Intelectuales. Buenos Aires, Nueva Vision.

DE SWAAN, Abram. (2001), Words of the World: The Global Language System. London, Polity Press.

EZCURRA, Ana Maria. (2011), Igualdad en Educación Superior. Buenos Aires, IEC-UNGS.

FOLLARI, Roberto. (2008), La Selva Académica. Rosario, Homo Sapiens.

GANTMAN, Ernesto (2011) La productividad científica argentina en Ciencias Sociales: Economía, Psicología, Sociología y Ciencia Política en el CONICET (2004-2008). Revista Española de Documentación Científica, Vol. 34, NE3, pp. 408-425.

GÉRARD, Etienne; WAGNER, Anne-Catherine. (2015), “Élites au Nord, Élites au Sud: Des Savoirs en Concurrence?" Cahiers de la Recherche sur l'Éducation et les Saviors, no 14 , pp. 7-24.

GERHARDS, Jürgen. (2014), “Transnational Linguistic Capital: Explaining English Proficiency in 27 European Countries". International Sociology, vol. 29, no 1, pp. 56-74.

HAGÈGE, Claude. (2002), No a la Muerte de las Lenguas. Barcelona, Paidós.

HEILBRON, Johan. (2008), "Book Translations as a Cultural World System". European Journal of Social Theory, vol. 2, no 4, pp. 429-444.

LARIVIÉRE, Vincent; HAUSTEIN, Stefanie; MONGEON, Philippe. (2015), “The Oligopoly of Academic Publishers in the Digital Era". Plos One, vol. 10, no 6, pp. 1-15.

LILLIS, Theresa; CURRY, Mary Jane. (2010), Academic Writing in a Global Context: The Politics and Practices of Publishing in English. London, Routledge.

LUCI, Florencia. (2012), “La Educación de los Dirigentes de Empresa: La Formación en Negocios y el Acceso a la Cúpula de las Principales Organizaciones", in S. Ziegler; V. Gessaghi (eds.), Formación de las Elites. Investigaciones y Debates en Argentina, Franciay Brasil. Manantial, FLACSO.

MOLTENI, Valeria; ZULUETA, M. Ángeles. (2002), “Análisis de la Visibilidad Internacional de la Producción Científica Argentina en las Bases de Datos SSCI y A \& HCI en la Década de 1990-2000: Estudio Bibliométrico". Revista Española de Documentación Científica, vol. 25, no 4, pp. 455-465.

PREGO, Carlos; VALLEJOS, Oscar. (2010), La Construcción de la Ciencia Académica. Buenos Aires, Biblos.

SEDLAC. (2015). Socio-Economic Database for Latin America and the Caribbean (CEDLAS y Banco Mundial). Fecha de acceso: 27 de octubre de 2015. 
Científicos Periféricos, entre Ariel y Calibán. Saberes Institucionales y Circuitos...

SPU. (2013), Anuario Estadístico de la Secretaría de Políticas Universitarias. Buenos Aires, Ministerio de Educación.

RETAMAR, Roberto F. (1971), “Calibán”. Casa de las Américas, no68, septiembre-octubre.

TIRAMONTI, Guillermina;ZIEGLER, Sandra. (2008), La Educación de las Elites. Aspiraciones, Estrategias y Oportunidades. Buenos Aires, Paidós.

VASEN, Federico. (2013), “Las Políticas Científicas Institucionales de las Universidades Nacionales Argentinas. Una Discusión de su Papel en el Sistema Nacional de Ciencia y Tecnología". Revista Ciencia, Docencia y Tecnología, Año XXIV, no 46, pp. 9-32.

WAGNER, Anne-Catherine. (2007), Les Classes Sociales dans la Mondialisation. Paris, La Découverte.

XAVIER DE BRITO, Angela. (2004), "Habitus de Herdeiro, Habitus Escolar: OSentido da Internacionalização na Trajetória dos Estudantes Brasileiros no Exterior", in A. Almeida et al. (orgs.), Circulação Internacional e Formação Intelectual das Elites Brasileiras, Campinas, Editora Unicamp, pp. 85-103. 


\section{RESUMO}

Científicos Periféricos, entre Ariel e Calibán: Saberes Institucionais e Circuitos de Consagração nas Publicações dos Pesquisadores do CONICET na Argentina

A Argentina possui um campo científico dinâmico, predominantemente públi$\mathrm{co}$, que triplicou a quantidade de pesquisadores em tempo integral na última década e repatriou mais de mil pesquisadores argentinos que haviam emigrado em épocas de crise. Paralelamente, no entanto, aprofundou-se a polarização entre os cientistas internacionalizados e aqueles de orientação mais endógena. Ainda que tendências autônomas e heterônomas convivam em todo o campo, foram consolidados circuitos segmentados de consagração, os quais evidenciam a disputa entre dois tipos de prestígio: um internacional versus outro local/nacional. Na primeira parte desse artigo, analisamos a morfologia desta elite acadêmica bifronte e descrevemos as suas formas de produção e circulação. Na segunda parte, concentramo-nos no perfil internacionalizado, através de um estudo empírico das publicações "mais relevantes" escolhidas por pesquisadores do Consejo de Investigaciones Científicas y Técnicas (CONICET) quando se solicita promoção.

Palavras-Chaves: Argentina; campo científico periférico; culturas avaliativas; publicações científicas; elites acadêmicas

\section{ABSTRACT \\ Peripheral Scientists, between Ariel and Caliban. Institutional Know-how and Circuits of Recognition in Argentina. The Publications of the researchers at CONICET}

Argentina is a dynamic scientific field, dominantly public, having witnessed a three-fold growth in the number of full-time researchers over the past decade and the repatriation of over one thousand researchers that had emigrated in times of crisis. Meanwhile, there has been a simultaneous deepening of the polarization between internationalized scientists and those with a more endogenous orientation. Although autonomous and heteronymous trends coexist throughout the field, segmented scientific circuits have been consolidated revealing the dispute between two types of prestige: one international and the other local/national. In the first part of this article, we analyze the morphology of this double-faceted academic elite, describing its styles of production and circulation. In the second part, we focus on the internationalized profile, by means of an empirical study on the publications considered to be the "most relevant" by researchers on the National Scientific and Technical Research Council (CONICET) when seeking for promotion.

Keywords: Argentina; Peripheral Scientific Field; Evaluative Cultures; Scientific Publications; Academic Elites 


\section{RÉSUMÉ}

Savants Périphériques entre Ariel et Calibán: Savoirs Institutionnels et Circuits de Consécration en Argentine. Les publications des chercheurs au CONICET

L'Argentine dispose d'un domaine scientifique dynamique, majoritairement public, où le nombre de chercheurs à plein temps a triplé au cours de la dernière décennie, grâce notamment au rapatriement de plus d'un millier de chercheurs argentins qui avaient émigré en temps de crise. Parallèlement, la polarisation entre les scientifiques internationalisés et ceux dont l'orientation est plus endogène s'est néanmoins approfondie. Encore que coexistent dans le champ ces tendances autonomes et hétéronomes, des circuits de consécration segmentés se sont toutefois consolidés et démontrent le conflit entre ces deux types de prestige: l'un, international, et l'autre, local/national. Dans la première partie de cet article, nous analyserons la morphologie de cette élite universitaire bicéphale et décrirons ses formes de production et de circulation. Dans la deuxième partie, nous nous concentrons sur le profil internationalisé à travers une étude empirique des publications "les plus important" choisi par les chercheurs du Conseil de recherche scientifique et technique (CONICET) pour appuyer leurs demandes de promotion.

Mots-clés: Argentine; champ scientifique périphérique; Cultures de l'évaluation; publications scientifiques; élites académiques

\section{RESUMEN}

Científicos Periféricos, entre Ariel y Calibán. Saberes Institucionales y Circuitos de Consagración en Argentina. Las Publicaciones de los Investigadores del CONICET

Argentina tiene un campo científico dinámico, predominantemente público, que triplicó la cantidad de investigadores full-time en la última década y repatrió más de mil investigadores argentinos que habían emigrado en épocas de crisis. Paralelamente, sin embargo, se profundizó la polarización entre los científicos internacionalizados y los que tienen una orientación más endógena. Aunque conviven tendencias autónomas y heterónomas en todo el campo, se han consolidado circuitos segmentados de consagración que evidencian la disputa entre dos tipos de prestigio: uno internacional versus otro local/nacional. En la primera parte de este artículo analizamos la morfología de esta elite académica bifronte y describimos sus formas de producción y circulación. En la segunda parte, nos concentramos en el perfil internacionalizado, a través de un estudio empírico de las publicaciones "más relevantes" que los investigadores del Consejo de Investigaciones Científicas y Técnicas (CONICET) eligen para solicitar promoción.

Palabras claves: Argentina; campo científico periférico; culturas evaluativas; publicaciones científicas; elites académicas 